\title{
Ecoacoustics and Multispecies Semiosis: Naming, Semantics, Semiotic Characteristics, and Competencies
}

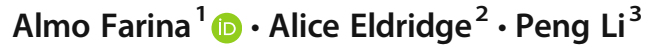 \\ Received: 15 September 2020 / Accepted: 25 January 2021 / Published online: 15 February 2021 \\ (C) The Author(s) 2021
}

\begin{abstract}
Biosemiotics to date has focused on the exchange of signals between organisms, in line with bioacoustics; consideration of the wider acoustic environment as a semiotic medium is under-developed. The nascent discipline of ecoacoustics, that investigates the role of environmental sound in ecological processes and dynamics, fills this gap. In this paper we introduce key ecoacoustic terminology and concepts in order to highlight the value of ecoacoustics as a discipline in which to conceptualise and study intra- and interspecies semiosis. We stress the inherently subjective nature of all sensory scapes (vivo-, land-, vibro- and soundscapes) and propose that they should always bear an organismic attribution. Key terms to describe the sources (geophony, biophony, anthropophony, technophony) and scales (sonotopes, soundtopes, sonotones) of soundscapes are described. We introduce epithets for soundscapes to point to the degree to which the global environment is implicated in semiosis (latent, sensed and interpreted soundscapes); terms for describing key ecological structures and processes (acoustic community, acoustic habitat, ecoacoustic events) and examples of ecoacoustic events (choruses and noise) are described. The acoustic eco-field is recognized as the semiotic model that enables soniferous species to intercept core resources like food, safety and roosting places. We note that whilst ecoacoustics to date has focused on the critical task of the development of metrics for application in conservation and biodiversity assessment, these can be enriched by advancing conceptual and theoretical foundations. Finally, the mutual value of integrating ecoacoustic and biosemiotics perspectives is considered.
\end{abstract}

Keywords Ecoacoustics · Vibroscape - Soundscape - Sonotope - Acoustic communities · Acoustic habitats $\cdot$ Ecoacoustic events

Almo Farina

almo.farina@uniurb.it

Extended author information available on the last page of the article 


\section{Introduction}

In recent decades sound has become recognized as a significant component of evolutionary ecospace (Hauser 1996; Kroodsma and Miller 1996) and core component of the ecosystem functioning within the ecological sciences (e.g. Qi et al. 2008). Environmentally concerned listening is not new, but previous treatments have tended to prioritize either human or ecological perspectives which has precluded sensible conceptualization of inter- and multispecies semiosis. The semiotic and ecological relevance of environmental sound have long been discussed in music composition (Westerkamp 2002) and communication studies, but these had a strong anthropocentric bias (Truax 1999: 52). Similarly, research on the effects of sounds on animal populations and communities dates back to the beginning of the behavioural studies (e.g. Clark and Karr 1979) but was not integrated with human study. The nascent field of soundscape ecology, defined by Pijanowski et al. $(2011 \mathrm{a}, \mathrm{b})$ as the study of the causes and consequences of sound across landscape explicitly brought human-environment relations into focus on the landscape scale. More recently still the study of the ecological role of sounds across species and levels of ecological organization has coalesced in the discipline of ecoacoustics, defined by Sueur and Farina (2015:2) "as a theoretical and applied discipline that studies sound along a broad range of spatial and temporal scales in order to tackle biodiversity and other ecological questions". Ecoacoustics investigates the ecological relevance of acoustic dynamics and patterns in the acoustic environment. Whereas bioacoustics focuses principally on the structure (anatomy) of sound as a biological signal that transfers information between individuals (Fletcher 2007), ecoacoustics considers sound to be a component in and an indicator of wider ecological processes and also investigates higher levels of organization, from community, through population to landscape scales. These parallel developments of interest in the dynamics and significance of the acoustic environment as carriers of meaning across and between species and their cultures and ecologies is testament to the relevance of environmental sound in contemporary environmental and ecological study across disciplinary divides. In the light of current environmental and existential crises, integrated approaches to the study of human-environment interactions are critical. Acoustic environments support and are created through biosemiotic exchanges between all species and their study holds promise in bridging species and disciplinary divides (Eldridge et al. 2020), however we currently lack a vocabulary that resonates across species and disciplines.

In every new discipline the development of concepts, language, methods, evidence and theory take time to evolve and aggregate into an emergent, homogeneous disciplinary body of shared principles, knowledge, accepted experimental frameworks and methods. In some sciences theory acted as forerunner: consider the ingenious and outstanding contribution of Claude E. Shannon to information and communication sciences (Shannon 1948; Shannon and Weaver 1949), Mandelbrot's vision of fractal mathematics (Mandelbrot 1983), or Laplace's atmospheric resonance hypothesis that has recently found support in observations of the space-time spectrum of the earth's atmospheric surface pressure (Sakazaki and Hamilton 2020). However, in ecoacoustics theoretical principles remain scarce (Farina 2014; Farina and James 2016; Farina and Gage 2017) comprising a handful of physiological, ecological and evolutionary hypotheses: the Morphological Adaptation Hypothesis (MAH), the Acoustic Adaptation Hypothesis (AAH), or the Acoustic Niche Hypothesis (ANH). 
The MAH considers the role of the body size as a biological constraint of the vocalization organs and their acoustic performance (Wallschläger 1980). The AAH refers to the adaptation of sound emitted by species to environmental characteristics (Morton 1975; Marten and Marler 1977; Lemon et al. 1981). The ANH proposes partitioning mechanisms with which species reduce the interspecific frequency overlapping (Krause 1993). However, the ANH is associated with pristine environments; we can question its theoretical tenability in perturbed environments, due to land use change or climate change which radically alter community composition, the latter causing shifts in acoustic phenology, and for modifications of signal parameters as time pattern or frequency range (Sueur et al. 2019). Ecoacoustic epistemology appears incomplete.

Ecoacoustic research to date has focused predominantly on the development of tools for environmental monitoring, rather than theoretical and conceptual development and explication (Sueur et al. 2008). Driven by the critical need for cost-effective conservation tools to face and mitigate environmental crises, coupled with the increasing availability of low-cost (e.g. Hill et al. 2018), robust acoustic recording technology, early ecoacoustic research has prioritised the development and validation of acoustic metrics as instruments for evidence-based conservation and land management. Ecoacoustic metrics provide statistical analyses of the distribution of sound energy across time and/or frequency and have been shown to be cost-effective proxies for core environmental characteristics such as biodiversity or habitat status. A significant research effort has been expended on the development and validation of proxies for biodiversity, or level of environmental integrity and degradation (Grant and Samways 2016; Harris et al. 2016; Krause and Farina 2016), and on environmental monitoring and environmental quality assessment (Tucker et al. 2014). These developments in computational ecoacoustics run in parallel with a body of research in computational bioacoustics which focuses on automated species recognition (Sueur et al. 2008; Gage and Axel 2013; Gasc et al. 2013a, b; Sueur et al. 2014). Many studies, some hybridising bioacoustic and ecoacoustic approaches, focus on the impact of anthropogenic noise on the acoustic performances of individual species (Brumm and Todt 2003; Brumm and Slabbekoorn 2005; Brumm and Slater 2006; Brumm 2010; Luther and Gentry 2013) or on community dynamics (Gil et al. 2015). Other studies have investigated the relationship between soniferous species and traditional biodiversity metrics, in aquatic (Desjonquères et al. 2015; Harris et al. 2016) and terrestrial habitats (Slabbekoorn 2004; Rappaport et al. 2020). At the same time, the monitoring of animal diversity (Depraetere et al. 2012) and applications in restoration ecology using acoustic indices is gaining popularity (Borker et al. 2019). As with much contemporary big data science across -omics disciplines, this focus on data and correlation-seeking misses an important step in traditional science: observation and theory building. The development of effective tools requires a richer theoretical basis, which in turn demands a deep revision and more precise specification of vocabulary.

Advancement of a unified epistemology has also been hampered by what we might understand as a convergent evolution of core concepts across different disciplines, resulting in some confusion in nomenclature, definitions, concepts and associations. For instance, initial naming and semantic uncertainty between soundscape ecology (Pijanowski et al. 2011a, b; Farina 2014) and ecoacoustics (Sueur and Farina 2015) has not favoured a unique line of epistemological development. Similarly, the fact that Acoustic Ecology (Schafer 1977; Wrightson 2000) was historically a humanistic 
endeavour which investigated the relationship between people and environmental sounds, with little attention paid to the role of acoustics in "non-human" ecology, has not encouraged integrated epistemological progress.

At the moment ecoacoustics has close relationships with other ecological disciplines like landscape ecology (Farina 2021). However, we consider it important for future research to reinforce the contacts with biosemiotics because sounds are such critical vehicles in communication and semiosis. To pursue this goal it is important to create a clear nomenclature in order to identify and investigate ecoacoustic objects, patterns and processes.

Language shapes thought and interacts potently with observation to build theory and advance knowledge. Linguistic relativity applies in science as in wider culture (Kay and Kempton 1984). Whorf famously asserted that "We dissect nature along lines laid down by our native languages" (Whorf 1956:213) and examples abound in which scientific progress has advanced following the naming of abstract concepts. For example, the coining of the term autopoiesis by Maturana and Varela (1991) to uniquely describe the processes of self-repair and self-maintenance that characterises life focused research on the teleonomic properties of organisms. More generally, nomenclature has been fundamental to modern taxonomy since Linnaeus' time. During the ontogenesis of ecoacoustics, the need for linguistic development in order to conceptualize, articulate, investigate and assess acoustic objects, and configurations and processes of ecological importance has been previously noted (e.g., Farina 2014).

The aim of this paper is therefore to present and refine the nomenclature and principles of ecoacoustics in order to clarify core ecoacoustic concepts (Table 1) and bolster biosemiotic perspectives (Fig. 1). Description of the patterns and processes, objects and agencies of the acoustic environment is fundamental for the advancement of ecoacoustics and its integration with other disciplines including biosemiotics and related disciplines in the humanities that are concerned with multispecies thinking.

\section{From Vibroscape to Soundscape}

In the development of a taxonomy in ecoacoustics we include the ecoacoustic objects and agencies as components of the family of the vivo-scapes. The vivo-scape is the field of existence or domain of an "ecological species" representing the totality of biological, ecological and semiotic interactions between an organism and its operational environment. The vivo-scape is the domain in which the senses of all organisms have a closure with the environment (Farina and James 2021).

Ecoacoustics to date has focused on air-borne vibrations heard as sound and soundscape has previously been defined as the acoustic component of a landscape (Farina and Pieretti 2014). However, it is increasingly recognised that substrate vibrations are ubiquitous in the environment (Hill 2009; Šturm et al. 2018), vibration receptors are frequent in organisms (e.g., Hill 2008; Narins et al. 2016; Sugi et al. 2018) and vibrational signalling is now considered one of the most ancient forms of communication across phyla and kingdoms (Cocroft et al. 2014; Endler 2014): sensitivity to vibrational signals is observed in bacteria (e.g., Reguera 2011) and plants (Appel and Cocroft 2014). It is useful therefore to distinguish between vibroscapes and soundscapes (Polajnar and Virant-Doberlet 2019; Virant-Doberlet et al. 2019). 
Table 1 Ecoacoustic Terminology

Acoustic community: an aggregation of species that produces sound by using internal or extra-bodily sound-producing mechanisms.

Acoustic eco-field: The spatial configuration of a soundscape as a carrier of meaning to track resources.

Acoustic habitat: The specific acoustic character of a geographical area selected as favorable by a species for living.

Acoustic signature: The sequence of sound that characterises a species, an acoustic community or sonotope.

Alpha biophonic diversity: Biophonic diversity inside an acoustic community.

Alpha sonotope diversity: Diversity of ecoacoustic events present in a sonotope.

Anthrophonies: Sound produced by human vocalizations transmitted and magnified by technological devices.

Audible sound: Vibrations with the range of hearing (between 20 to $20 \mathrm{k}$ Hertz for humans).

Biophonic diversity: Diversity of sounds produced by an acoustic community.

Beta biophonic diversity: Biophonic diversity between two acoustic communities.

Beta sonotope diversity: Diversity of ecoacoustic events between two sonotopes.

Biophony: Sound produced by vocal organs or body parts of species or the results of friction of animal body with substrate, vegetation or air.

Dawn chorus: the collective acoustic activity of an acoustic community around sunrise.

Dusk chorus: the collective acoustic activity of an acoustic community around sunset.

Ecoacoustic diversity: Diversity of ecoacoustic events produced by a landscape.

Ecoacoustic events: Acoustic signals that after an interpretation have the capacity to influence behavior and ecology of the listeners.

Far field: Portion of soundscape that is sensed but does not produce changes in the behaviour of organism.

Gamma biophonic diversity: Total biophonic diversity in a landscape.

Gamma sonotope diversity: The diversity of ecoacoustic events in a landscape.

Geophony: Sounds produced by abiotic agents like wind, rain, eruptions, flowing water.

Interpreted soundscape: Portion of soundscape which is assigned a specific meaning and acted upon.

Latent soundscape: Portion of vibroscape that is not perceived by a particular individual as sound but that can be heard by others.

Near field: Portion of soundscape that produces changes in the behavior of an organism.

Noise: Sound that interferes with acoustic communication.

Sensed soundscape: Portion of the vibroscape perceived by an organism as sound.

Soniferous species: A species that makes acoustic signals to communicate.

Sonotone: Area at the edge of sonotopes.

Sonotope: A homogenous unit of a soundscape.

Soundscape: Part of vibroscape perceived as sound by an organism.

Soundtope: A homogeneous unit of soundscape consisting solely of biophonies.

Soundtone: Area at the edge of soundtopes.

Technophony: Sound produced by the functioning of machineries.

Vibroscape: The entire set of vibrations that is present in a specific portion of a geographical area.

Vibrotope: A homogenous unit of vibroscape.

Following (Šturm et al. 2018) we define the vibroscape as the entire set of substrate or airborne vibrations that is present in a specific portion of a geographical area. In physical terms, vibration is a quick moving back-and-forth (or up and down) motion of particles about a point of equilibrium. Frequency is the number of these oscillations in a given time. 


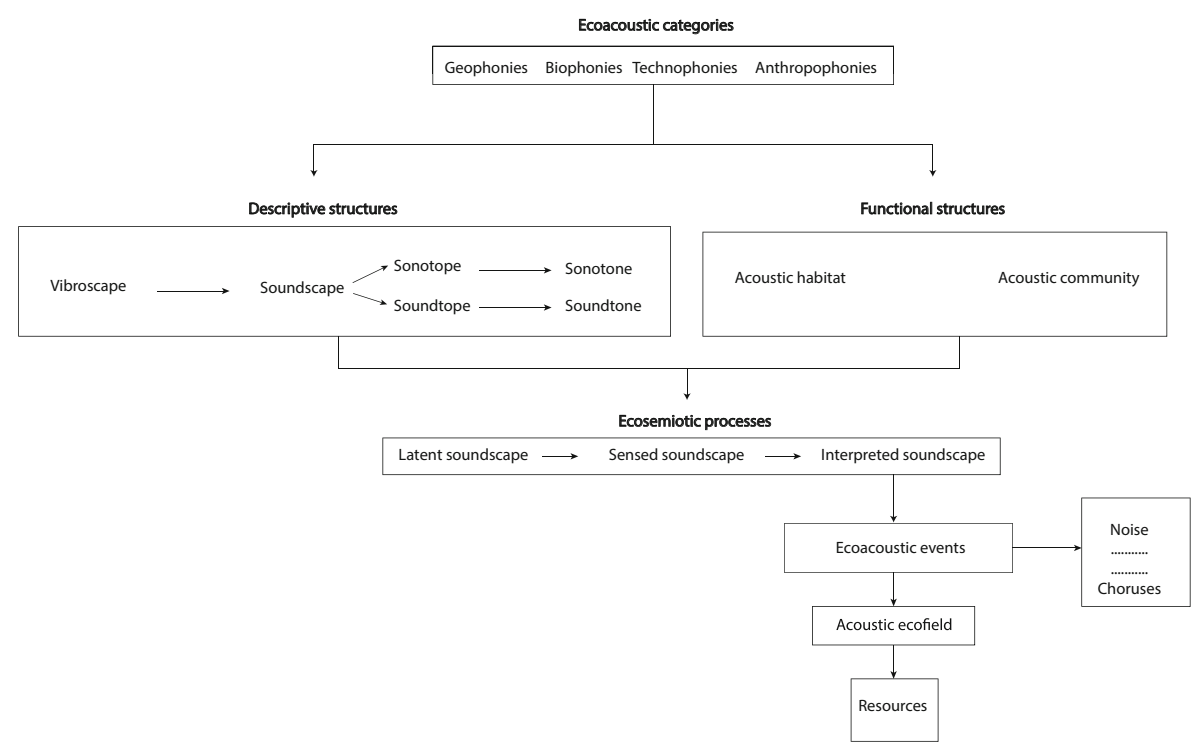

Fig. 1 Conceptual representation of core ecoacoustic elements and their functional relationships

The energy emitted during vibration is not constant because vibrational transmission is determined by physical properties of the solid, liquid and gaseous medium through which vibrations travel: temperature, salinity, shape of the surfaces, pressure, density, attrition, etc. When a vibration from an elastic body passes through air or water transmits such vibration to a receiving organism's organ of hearing, it can result in a mental sensation, namely sound. Sound is a typology of energy that is utilized passively or/and actively by a great number of organisms returning an important multifunctional sensorial scape. Soundscape can therefore be usefully understood as the portion of vibroscape converted by special sensor into electrical signals that in turn are converted into an acoustic sensation at the brain level.

According to a physical description, sound is a type of structured-perceivedenergy that propagates in the air approximately at $331 \mathrm{~m} / \mathrm{s}$ at $0^{\circ} \mathrm{C}$, and five times faster $(1484 \mathrm{~m} / \mathrm{s})$ in water. Sound is modified by diffraction, reverberation and by absorbent properties to the medium and its perceived quality (ranging effect) depends on position and distance of receivers compared with the position and energy of sources. Sounds according to the frequency of vibration adapted to a human auditive capacity are classified as infrasounds ( $<20$ to $0.001 \mathrm{~Hz})$, audible sounds (20 to $20,000 \mathrm{~Hz}$ ), and ultrasounds (from $20 \mathrm{kHz}$ to several gigahertz).

From a biosemiotic point of view, sound is a vehicle of meaning perceived as a signal by species specific acoustic sensors (i.e. inner ear in vertebrates, tympanal organ in insects) and transformed into mental sensation and codified, or interpreted to assign a meaning or create an effect.

We therefore define soundscape as the part of the vibroscape (Šturm et al. 2018) converted by specific organs and successive cognitive process into sounds and composed of a collection of ecoacoustic events (signals) that after an interpretation have the capacity to influence behavior and ecology of the listeners. 


\section{Soundscape Sources}

Components of the soundscape can be usefully differentiated according to their assumed sources; at least four can be identified from a human perspective geophonies, biophonies, technophonies and anthropophonies. Geophonies result from the molecular friction of abiotic and biotic material and generate a great variety of sounds, including rain, wind, thunder, volcanic eruption, water fall, etc. (for more details on the acoustics of friction see Akay 2002). Biophonies are traditionally considered to result from signals created intentionally by soniferous organisms for a range of different purposes (habitat assessment, navigation, territory or group defence, mating, feeding, roosting, pleasure etc.). From ecological and semiotic perspectives we should also considered the unintentional sounds produced by the friction of animal body with vegetation, soil or air (e.g., the flapping of the wings in the air, scraping of feet on the ground). Technophonies describe those sounds that originate in mechanically augmented human activity and are produced by moving vehicles (train, car, ship, airplane) and by machineries. To these three typologies of sounds we must add every vocalization produced by humans and instrumental music as well. Human vocalizations should be considered biophonies but are often artificially amplified and remotely broadcasted (radio, television) or emerging from social events like sport competitions (football, tennis, athletics) that concentrate a great number of shouting people and for this it is reasonable to recognize the category of anthropophonies. A complex soundscape highly variable in time and space results from the merging, overlapping and reciprocally masking processes between these four sources of sound (Farina 2014; Farina and Gage 2017). These categorizations like other more specific schemes in urban contexts (e.g., Niessen et al. 2010; Davies et al. 2013) are functional from an anthropocentric perspective, but are unlikely to be relevant across species. They are useful in applied investigations of landscape restoration and management as indicators of relative activity of actors in the landscape, although conceptual and perceptual exceptions can be readily identified from a human perspective: for example a fast flowing river is indifferentiable from a motorway in certain conditions, and their perceptual relevance to other species is doubtful: cicada reputedly respond to lawn mowers and other low frequency technophonies and frogs respond to the passage of a tractor.

\section{Spatial Scales of Soundscape Agencies}

Due to the dissipative nature of energy as it travels through any medium, vibroscapes and soundscapes are heterogenous in space and time (see also below for relationship between landscape and soundscape structure). It is therefore useful to approach vibroscapes and soundscapes at different spatial scales.

In ecology the term ecotope was introduced to designate the fundamental unit of ecological plant sociology by Sorensen (1936) and later elaborated by Tansley to describe the particular portion "of the physical world that forms a home for the organisms which inhabit it." Tansley (1939: 228). The coining of this term delineates and brings into focus an organism-centred, homogenous space in an otherwise heterogeneous landscape. In the same way, we can identify perceived units within the vibroscape and soundscape as vibrotopes and sonotopes that are characterized by particular vibrational and acoustic signatures. These signatures are amenable to 
computational analysis, opening up investigation of interactions that shape the evolution of vibrational and acoustic communication, as well and advancing understanding of ecological processes and ecosystem dynamics (Sturm et al. 2018). The sonotope in a flat geography has stellar-like morphology where a receiver is at its centre and the perceptual efficiency depends on the loudness and distance of the source. The terms far field and near field are used to describe the long and close range of perception, respectively (Farina and James 2016). If sound sources are distributed evenly all around the receiver this stellar-like field should take the form of a double ring, with a first ring (near field) included in a second ring (far field). The threshold between near and far field can be identified empirically and is significantly shaped by landscape variables like land aspect and vegetation structure; for example, sounds from a narrow valley will create an irregularly perceptual range. Near and far field influence the ranging behaviour with which a species decides on the importance of an acoustic signal in modifying its behaviour (Farina 2014:72-82; Ringler et al. 2017). The acoustic signatures which characterize a particular spatially delimited sonotope also vary dynamically. According to the temporal scale at which acoustic information is empirically aggregated it may be relevant to investigate acoustic signatures at different timescales from hourly, daily, monthly, seasonal resolution, etc. Identification and monitoring of these signatures supports acoustic phenology.

Soundtope describes the biophonic component of a sonotope and can be considered as the acoustic emissions of an acoustic community (see below). These have previously been defined by Farina (2014: 17-19) as a portion of biophonies that is perceptually distinct by a listener.

Finally, in classic ecology, the term ecotone differentiates "the tension belt between adjacent communities" (Tansley 1939: 215) in a land mosaic. Similarly, the borders between sonotopes create a very complex acoustic condition that we define as acoustic ecotones or sonotones; consider for example, the sensation of walking between sound-systems at a music festival or listening as you swim above and below water on a coral reef.

\section{Specificity of Soundscapes}

From this emerging semiotic position, soundscapes can only sensibly be considered from an organism-centered perspective. Just as "there are as many worlds as there are subjects" (von Uexküll 1926: 70) each organism experiences a unique soundscape shaped by the specificity of its biological receptors and semiotic sensitivities. The term ecosystem does not require a further specification but only eventually an adjective like "terrestrial", "aquatic", "urban" etc. In contrast, all scapes (land-scape, tactile-scape, thermal-scape, odor-scape, vibro-scape, sound-scape) are semiotic agencies (Enfield and Kockelman 2017) or potent carriers of meaning and significance; to be correctly used they require a further organismic ascription, recognizing that they arise only through the result of a situated, organism-specific process of sensing and interpretation. This organism-centered perspective follows Uexküllian Umwelt in recognizing the meaning-making subjectivity of each organism in its interaction with the environment (Tønnessen 2009; Tønnessen et al. 2018).

In von Uexküll's original formulation each organism's "private" world is composed of an inner world, a world-as-sensed and a world-as-action; this private world exists 
within a surrounding-world and allows species to coexist in the same habitat with a minimal inter-specific competition (von Uexküll 1926; von Uexküll 1982, 1992). In the current literature across arts, humanities and sciences landscape, vibroscape and soundscape are used without the necessary specification and become too generic like the term habitat in classic ecology (e.g., Hall et al. 1997). Historically in the humanities literature, landscape and soundscape have been purveyors of human sensations and spiritual values (Mallarach 2008), although this is changing with multispecies thinking across conservation, anthropology and feminism in the wider humanities. It is within these emerging multispecies paradigms that we propose ecoacoustics has enormous potential. Acoustic signatures hold rich multispecies significance, ecoacoustics develops a conceptual and methodological tool box for investigation of these interactions, offering a point of contact between anthropological and ecological phenomenon and the natural sciences and humanities, so bridging the human-environment rift in contemporary academia.

We propose that landscape and soundscape should always be qualified with an organismic attribution at whatever taxonomic level is relevant to the case in point: beetle landscape (e.g. Wiens and Milne 1989), blackbird soundscape (e.g. Farina et al. 2011), etc. As for landscape, we refer to a generic soundscape as perceived by people (a synonym of human soundscape) and the majority of research utilizes this term with this implicit acceptation. Although we promote an organism-centred perspective we also acknowledge the impossibility of comprehending the experience that denotes: What does the blackbird (Turdus merula) soundscape sound like to the blackbird? We cannot know. But the sensorial capacities and semiotic sensitivities of blackbirds can be inferred, even if they are not accessible to others. An indirect way to describe the blackbird soundscape, for example, is to suppose that the spatial variation of abundance of the conspecifics may represent a proxy of soundscape preferences; playback experiments also provide insight into discriminative sensitivities between species (see Francis et al. 2017 for a comparison between human and Brewer's sparrow (Spizella breweri)). We elaborate this point in the section dedicated to the Acoustic Habitat below (Mullet et al. 2017).

Having recognized the intrinsically subjective nature of "scapes", we can distinguish three levels of perception according to the sensory capacities and semiotic sensitivities of a particular organism (Farina 2006). Refining the nomenclature previously outlined in Landscape Theory (Farina and Pieretti 2014) we propose a distinction of soundscapes in three categories: Latent, sensed and interpreted landscape. The latent soundscape (LS) is the portion of air-borne vibrations that cannot be perceived by a species as sound because they lie beyond the acuity of its hearing receptors (sounds that lie outside frequency range, as in infrasound and ultrasounds for humans, or below the amplitude threshold). Whilst of no significance to an individual organism or species, LS can be considered a potential source of information in which evolutionary processes play out (Farina and Pieretti 2014) even if they are not a carrier of significant meaning for a particular organism; from the organismic evolutionary perspective, this includes signals that historically did not confer an evolutionary advantage for that particular species, meaning that neither it's sensory nor cognitive systems are tuned to it. Sensed soundscape (SS) describes the portion of the acoustic information that a particular organism is sensitive to but are not necessarily integrated into a physiological or behavioural reaction. This is the portion of vibroscape that hearing organs are sensitive to (approximately $20 \mathrm{~Hz}$ to $20 \mathrm{kHz}$ 
for humans). Such information has been defined by Reading (2011:9-15) simply as "data" (patterns that are potentially meaningful). Finally, the interpreted soundscape (IS) is the subset of SS that makes a difference to the organism. This soundscape comes into being when the recipient has the opportunity and motivation to assign a meaning to external acoustic signals. Such signals are transformed by a biosemiotic process into signs and, finally, by a cognitive system into meaning, (e.g., sound descriptors related to human perception, Davies et al. 2013). Genetic, cognitive and cultural codes are used by species to assign a meaning and transform signals into signs (Barbieri 2009). These terms are valuable in enabling us to differentiate between objective, or universal vibrations and conventional signals (Barbieri 2006).

Importantly we begin to build a nomenclature to bridge biosemiotics across multiple species and disciplines. In being organism-centered the categories are fluid in the face of changes to internal state of organism, or changes in receptor sensitivity, including technological transductions in the case of humans and some animals. Science has always been driven by technological advances affording greater acuity, and we note that Ecoacoustics (Sueur and Farina 2015) and Biotremology (Hill et al. 2019) are similarly driven by advances in acoustic and vibrational transducers that enable us as humans to perceive and speculate on the meaning of signals that lie beyond the range of our naked biological auditory systems (in space and time as well as frequency) for ourselves and other organisms.

\section{Soundscape Agencies and Semiosis}

To further elaborate the concept of soundscape as a semiotic agency, we consider the ways in which the acoustic signature of a specific sonotope is a potent carrier of information in the environment. From our anthropocentric perspective (selecting humans as focal species) we are familiar with the experience of localizing an unseen waterway in a landscape by listening for changes in position and loudness of water sounds. And all species appreciate different acoustic conditions as they move across a landscape in relation to the sources of sound, their position and loudness. For instance, moving from the suburbs to an urban centre we often experience the reduction of sounds from soniferous species as vegetation cover is more fragmented and reduced. Similarly, at a larger spatial scale, sounds produced by soniferous species decrease along a countryside-urban gradient. We can say that at every location across a landscape a specific organism-centred soundscape arises. This dynamic frame allows fast-moving species like birds or insects to rapidly infer information in a short time and to generate meaningful and accurate maps of acoustic signals that become carriers of meaning for the localisation and acquisition of resources.

\section{Acoustic Habitat Selection}

Acoustic signals also play a key role in habitat selection. During habitat selection species search for portions of the environment that offer all the necessary resources in terms of refuge, breeding space, food supply, protection from predators, etc. There is empirical evidence that acoustic cues also play a key role in habitat selection for birds (Mullet et al. 2017) as well as crustaceans, pelagic larvae of reef fish (Jeffs et al. 2003; Simpson et al. 2005, 2008; 
Tolimieri et al. 2000), and even coral polyps (Vermeij and Bak 2002). Acoustic cues used by conspecifics or heterospecifics are considered public information (Danchin et al. 2004; Boulinier et al. 2008). Mukhin et al. (2005) found that Eurasian reed and sedge warblers use acoustic cues of conspecifics and other species to select the more suitable wetlands during migration. This behaviour can be explained by the heterospecific (acoustic) attraction hypothesis (Mönkkönen et al. 1990). For instance, Thomson et al. (2003) have experimentally manipulated the density of titmice in Northern Finland and have found that the number of chaffinch (Fringilla coelebs), that are migratory birds in this region, increased their settlement in the breeding areas with a high number of titmice. The acoustic activity of the titmice community influenced the choice of chaffinch breeding areas. Several species use the social cues of conspecifics to select a suitable breeding habitat, including American redstarts (Setophaga ruticilla) (Hahn and Silverman 2006), blackcapped vireos (Vireo atricapilla) and black-throated blue warblers (Dendroica caerulescens) that identify successful breeding habitats using conspecific cues and avoid equally suitable habitats without those social cues (Ward and Schlossberg 2004; Hahn and Silverman 2007). Further experiments conducted on black-throated blue warblers, have coerced individuals to adopt habitats of poor quality by manipulating social acoustic cues (Betts et al. 2008). Madden and Jehle (2017) have experimentally proven that the great crested newt (Triturus cristatus) is influenced during breeding migration by calls from sympatric (Rana temporaria and Bufo bufo) and allopatric (Lithobates catesbeianus) anurans. Many species, especially birds are sensible to the quality of soundscape and avoid noisy environments or modify their acoustic behaviour (Ortega 2012).

\section{Ecoacoustic Events}

Due to the difficulties of understanding the "true language" of soniferous species in practice, we tentatively utilize an aggregation of acoustic signals that will be submitted to an inferential analysis. These signals, that for convention we call ecoacoustic events (EE), may be considered a sub-set of sonotopes, and are homogeneous for some intrinsic characters like intensity, temporal and frequential distribution, etc. (Farina et al. 2016, 2018). EEs are the acoustic equivalent of a green lawn for an earthworm searching for a blackbird; they are a source of information throughout the life cycle of a species. We believe that a species can receive information from an EE, but the duration of it's efficacy will be dependent upon the current needs and physiological status of that particular organism and is not something we can easily infer. A species can receive information according to the need that at that time must be satisfied. Each EE requires a decoding procedure to be incorporated into a mental representation that is assigned a definitive meaning.

\section{Acoustic Eco-Field}

In cognitive ecology and ecosemiotics the concept of eco-field has been defined by Farina and Belgrano $(2004,2006)$ as a carrier of meaning to perform a specific function finalized to intercept resources. The eco-field hypothesis is a special case of ecosemiosis based on the spatial arrangement of objects which are carriers of meaning connected to the activation of a 
specific (vital) function. In this case the signs are based on a spatial configuration of the objects (like trees, shrubs, or other organisms) that is recognized as a carrier of meaning. In this process a cognitive template (the "searching image" in ethological jargon) is mentally compared with the surrounding context, until an overlap occurs. Cognitive process associated with the eco-field bridges between information, cryptic resources and organisms.

To better understand acoustic semiosis we introduce the concept of acoustic eco-field as an acoustic template that is used according to a function to intercept a specific resource. Acoustic eco-fields are the cognitive templates utilized in the acoustic communications to conjugate different semiotic mechanisms that utilize for instance visual, acoustic, tactile sensory information.

In acoustic semiosis we can distinguish acoustic eco-fields used to defend a territory (aggressive calls), to select a partner (song), to signal predator presence (alarm calls), or individual position (contact calls), etc. The modulation of every acoustic signal becomes part of an acoustic eco-field. In synthesis, from an ensemble of acoustic signals coming from the surroundings species, according to the physiological needs, an individual selects and decodes acoustic signals and assigns a specific meaning.

The temporal integration of acoustic signals is function- and species-specific, according to the decoding procedure at play. Acoustic eco-fields require a precise temporality that assumes the same role of space/form in visual eco-fields: hourly, daily and seasonal cycles of an organism are based on the activation of some functions in turn linked to a specific physiological need. The daily routine of a bird is characterized by a precise temporality: for instance, a songbird has a peak of song activity at dawn, then in the middle of morning and finally at dusk (Farina et al. 2021). Foraging activity is more continuous, alternating between active searching with resting periods. Roosting time may be longer in the afternoon and for diurnal species lasts a specific period according to the astronomical length of the night.

For each behaviour, according to the eco-field hypothesis, a specific material (e.g. food) or immaterial resource (e.g., safety, territory control, intraspecific contacts) must be intercepted. In this way, every organism has the capacity to scan the acoustic surrounding (Todt and Naguib 2000), differentiating the signals received according to the function that has activated at that time. For instance, in territory defence a bird will pay attention to the territorial songs sung by other intra-specific individuals. During foraging activity contact calls of other species that could indicate abundance of food in the surroundings or the approaching of a predator are attended to. During the feeding of chicks, adults pay attention to alarm calls issued by other individuals as a signal of possible intrusion of predators.

\section{Acoustic Communities}

The acoustic community is defined as an aggregation of species that produces sound by using internal or extra-body sound-producing tools (Farina and James 2016). The acoustic community interacts inside a portion of a sonotope and is the source of distinct biophonic signatures, or soundtope (Farina and James 2016). An acoustic community generates the biophonic field in which species and organisms interact with each other. Ecoacoustic research methods and analysis procedures predominantly focus on the recording and processing of the biophonic signals of these acoustic communities in terrestrial and aquatic environments (Drewry and Rand 1983; Price 1984; Sueur et al. 2008; Luther 2009; Gasc et al. 2013a, b; Lellouch et al. 2014). The acoustic community is a 
central concept to theoretical and empirical ecoacoustics and deserves a deeper discussion.

In this narrative we have to consider that an acoustic community is not only the assemblage of all soniferous species acoustically active in a specific moment (in this case the model assumes that all the sounds emitted by the species are detected in the same way by a listener) but also that not all the species are detected by an individual listener. Due to different acoustic activities of species the temporal limit of an acoustic community can be obtained only probabilistically, whether by a human, other organism or computational listening algorithms. An acoustic community can be assessed by listening, recording and analyzing the acoustic signals emitted from the member (soniferous) species. The sonotope of an acoustic community often includes nonbiological sounds and the isolation of it's biophonic signature for analysis is not always simple, especially when geophonic and technophonic sounds overlap biophonies with masking effects that impede the distinction of the ecological role of animal communication. Wind rain and traffic are very common sounds that mask biophonies, an issue for biological semiosis as well as computational analysis.

The acoustic community is distinct from a "traditional" ecological community because it is composed only of soniferous species and changes dynamically as they vocalize. This is the first limit in the application of this model to the regular ecological practice. Biophonic diversity assessment is based on the assumption that soniferous species are a reliable proxy for all species present in a location and that the acoustic community is representative of the wider ecological community, at that time and place. This assumption is certainly valid in terrestrial ecosystems where, for instance, bird species are well recognized as reliable indicators of wider biodiversity (BirdLife International 2013).

A further inherent limitation of the acoustic community concept stems from variations in the quality and quantity of acoustic performances of the component species and individuals. Some species are very active and sing loudly (e.g. warblers (Sylvia sp.) and others have acoustic performances limited in intensity and time like shrikes (Lanius sp.) or finches like Eurasian bullfinch (Pyrrhula pyrrhula). Just as an organism's hearing apparatus is sensitive to certain sounds, any particular computational analysis may be more or less sensitive to certain calls. These caveats all require further investigation, but despite these limitations the concept of the acoustic community remains central to ecoacoustics. For this, we assume that acoustic communities are variable in species composition with a species turnover along the day and along the season. The presence of some species in an acoustic community may be an indicator of the quality of the environment, but the concept of acoustic community is subordinate to the capacity of a listener. The use of this concept often is restricted to human perspective and the acoustic community becomes functional to a better description of the ecological processes. We assume that other species that perceive sounds may use a collective sound of an acoustic community to explore their surroundings, to optimize food search, to select the best habitat, etc. (Dall et al. 2005).

The different temporal aggregations of the acoustic community reveal important patterns; recent investigations reveal changes between (Eldridge et al. 2018) and within (Farina et al. 2021) species throughout the day. We can usefully differentiate diurnal and nocturnal acoustic communities. At dusk and at dawn specific communities appear, 
these communities are called dawn and dusk communities and are associated to dawn and dusk choruses (Burt and Vehrencamp 2005; Dabelsteen and Mathevon 2002).

\section{Ecoacoustic and Biophonic Diversity}

While the ecoacoustic diversity can be defined as the combinantion of the relative abundance and intensity of the different ecoacoustic events present in a soundscape (soundscape diversity) or in a sonotope (sonotope diversity), the term biophonic diversity is used to describe the number and relative importance of biophonic signatures that compose an acoustic community. We could say that biophonic diversity is the diversity of the acoustic community, in the same way that in ecology we use biodiversity as the diversity of a community. This has been demonstrated to provide a costeffective proxy for the ecological biodiversity (e.g., Sueur et al. 2008; Gasc et al. 2013a, b; Harris et al. 2016; Gibb et al. 2016; Krause and Farina 2016; Eldridge et al. 2018; Farina 2019a). As for "traditional" biodiversity nomenclature (Whittaker 1960) we identify three types of biophonic diversity: alpha, beta and gamma biophonic diversity. Alpha biophonic diversity is evaluated from the number of biophonic signals inside an acoustic community. Beta biophonic diversity describes the difference between acoustic communities; finally gamma biophonic diversity is calculated between acoustic communities across a landscape.

At the level of sonotope, the alpha sonotope diversity consists in the number and abundance of ecoacoustic events present in a sonotope. The beta sonotope diversity describes the difference in ecoacoustic events between sonotopes, and the gamma sonotope diversity is the total number of ecoacoustic events at soundscape/landscape scale.

In areas like the tropics where frequency partitioning (especially for insects) is well delimited, the biophonic diversity in the frequency domain predicts the presence of different species, and biophonic diversity more clearly corresponds to the diversity of species. However, in temperate and boreal biomes often the dominant species are birds and their frequential repertoire is larger. Some species like song thrush (Turdus phylomelos) may use in the singing composition a great spectrum of frequency (Deoniziak and Osiejuk 2019) and this reduces the correspondence between diversity of biophonic diversity and number of species.

While the biophonic diversity still requires a significant amount of human effort and complex pattern recognition procedures, the ecoacoustic diversity can be measured from ecoacoustic metrics adopting automated procedures (e.g. Farina et al. 2018).

\section{Choruses}

Choruses are a unique expression, or performance, of the acoustic community and are phenomena characterized by the contemporaneous vocalization of different species. They are found across the globe, common to soniferous species across phyla (insects, shrimps, fish, frogs, birds, and mammals), in terrestrial, in freshwater and marine biomes (Cato 1978; D’Spain and Batchelor 2006). Choruses have attracted the attention of scientists for decades and remain an enigma in terms of role in species adaptation and evolution (Allard 1930; Leopold and Eynon 1961; Shaver and Walker 1930; Wright 1912, 1913) and largely conjectural with a strong component of male-female coevolution (Walker 1969; Greenfield et al. 2016). In birds, for example, choruses have 
been explained in terms of circadian cycles, self-stimulation, mate attraction, mate guarding, territory defence, social dynamics, low predation, acoustic transmission, inefficient foraging and unpredictable conditions (Staicer et al. 1996). The acoustic transmission hypothesis (Morton 1986) proposes that higher level of singing (in birds) occurs when the song is less distorted by air turbulence. This seems a good, if not unique candidate, to explain the appearance of choruses at dawn and at dusk.

During choruses all individuals of a species are singing at the same time with an apparent overlap and potential masking; in a recent paper Malavasi and Farina (2013) report coordinated interspecific mechanisms that utilize a complex form of behaviour to exclude signal jamming in heterospecific choruses. We can expect that in acoustic communities living in untouched habitats, coevolutive processes may have favoured the creation of choruses that reinforce the intracommunity cohesion and reduce competitive masking. In winter time, in temperate biomes choruses of European starling (Sturnus vulgaris) are present also at noon. The meaning of these midday choruses for this species remains largely unexplored, but an exchange of information about the source of food may be activated due to evident capacity of this species to perceive auditory scenes (MacDougall-Shackleton et al. 1998). Chorusing is an important ecoacoustic phenomenon that is of great interest in environmental monitoring especially in relation with climate change (Sueur et al. 2019). The severity of weather has a great influence on intensity and duration of choruses.

\section{Noise}

The ability to detect, recognize and interpret a sound is not only dependent upon it being within an organism's hearing range but depends upon it's ability to discriminate and recognize an acoustic signal from an acoustic background of incoherent, or random sound that is referred to as noise. In acoustic physics, noise refers to a random oscillation in a signal with different spectral density spreads being described by different colours (white, pink, brown, red, blue, violet, black etc.). Signal-to-noise ratio describes the level of a desired signal relative to the level of background noise and is a physical property described in many fields of the scientific research from statistics to seismology, optics and biological time series (e.g., Scales and Snieder 1998; Ideker et al. 2011).

From a physical perspective noise cannot be distinguished from sound because both are vibrations; but the latter differs cognitively because it is associated with a meaning by receivers. Noise can be understood from information theoretic, acoustic or psychoacoustic perspectives and serves us in developing ecoacoustic theory, relevant to sensory and semiotic processes of living organisms. In turn, better understanding of the role of noise in semiotic terms may enhance development of next generation of ecoacoustic metrics for environmental monitoring; understanding the impact of vibrational emissions on other species' semiosis holds promise for mitigation through design and legislation.

Often we identify noise with technophonic sounds, in reality many technophonic sounds, like the sound of ambulances, the engine of a farm tractor, a church bell have a well established internal spectral structure, and meaning. These sounds can be considered annoying or unwanted for people but may elicit specific reaction in other organisms, for example frogs that have been observed to start their chorus at the close passage of a farm tractor. 
From a behavioural perspective, noise may therefore be considered as acoustic energy that interferes with the communication between a signaler and a particular receiver (Luther and Gentry 2013), often masking or impeding communication between organisms (Truax 1999), or an organism's perception and interpretation of signals in a given latent soundscape. Noise can limit the ability to receive acoustic information (Barber et al. 2010; Francis and Barber 2013). However in ecology noise can concur to assess a favourable acoustic habitat (Mullet et al. 2017). In fact, noise and acoustic habitat are in a strict relationship: some soniferous species avoid areas where noise is dominant or too high favouring the expansion of more noise tolerant species (Francis et al. 2009).

Many environmental noises approximate white noise (intense rain, urban noise, traffic, wind, river falls) and the physical noise concept can be used to model and to manage environmentally unwanted sounds (Brown 2010). In psychoacoustics sound is perceived as noise according to the circumstances and the organism's perceptual and semiotic sensitivity. For instance, the traffic produces a sound that can mask many other sounds, for this reason we consider such sound as noise in that it has a very low inherent acoustic information. Usually, urban noise is considered by people as an environmental threat that produces annoyance and on long period may affect human well-being (Babisch et al. 2005). Noise also has deleterious effects on several species in terrestrial (Barber et al. 2009) and in aquatic environment as well (Whitefield and Becker 2014; Frisk 2012). Noise is per se an acoustic event that can have some significance for an organism. Probably, animals discriminate noise from a signal in the same way is done by humans.

Some organisms neutralize the effect of noise by adopting different strategies: these include changing the amplitude of the acoustic signals (Lombard effect, Lombard 1911), changing frequency (Narins et al. 2004), changing signal redundancy (Potash 1972; Wiley 1994; Brumm and Slater 2006; Díaz et al., 2011), and changing behaviour (Lupo et al. 1991; Rabin et al. 2006; Chan et al. 2010). Changes in global transport and industry during the recent COVID19/20 global pandemic has provided unprecedented opportunity to measure the impact and absence of technophony on organisms, and investigation of associations between industry and ethology (Silent Cities https://osf.io/h285u/, accessed 25 August 2020).

\section{Ecoacoustic Competencies and Biosemiotic Perspectives}

The first phase of Ecoacoustic research has advanced understanding in at least five areas:

[a]. Acoustic patterns of soniferous species.

[b]. Soundscape quality.

[c]. Ecological phenomena.

[d]. Application of acoustic patterns in land management.

[e]. Ecoacoustics and biosemiotics. 
[a]. Acoustic patterns of soniferous species.

Convincing evidence exists that the acoustic activity of species responds to physiological and environmental constraints (e.g. Block 2005) (astronomic rhythms, light intensity, air temperature and humidity, wind and rain intensity, barometric pressure, etc.) that create regular patterns that can be observed at the level of:

1. Acoustic behaviour.

2. Seasonality of acoustic activity of species.

3. Daily rhythms (e.g. dawn and dusk chorus).

4. Responses to climate and weather dynamics.

\section{[b]. Soundscape quality.}

The human responsibility to preserve the quality of the soundscape is becoming central in the conservation and restoration agendas. For instance, human activity, spread everywhere on the Earth from marine to terrestrial ecosystems is producing environmental problems like noise. Mitigating noise is an important issue in urban areas (Magrini and Lisot 2015) but also in hybrid nature (Farina 2019b) and especially in marine systems (Prideaux and Prideaux 2016).

\section{[c]. Ecological phenomena.}

Ecoacoustic methods are proving to be powerful, cost-effective tools for environmental investigation and we see value in exploring phenomena central to ecological phenomenology (Eldridge et al. 2016). Subjects that could be investigated by applying an ecoacoustic approach include:

1. Environmental resilience and complexity of the acoustic communities (frequency partitioning).

2. Intensity and quality of acoustic species-specific performance in source and sink conditions.

3. Turnover of the acoustic communities along successional stages.

4. Biogeography of species-specific dialects in a metapopulation system.

5. Landscape structure and acoustic patterns:

5.1 Fragmentation and acoustic complexity.

5.2 Acoustic complexity at ecotones.

5.3 Land management and acoustic complexity maintenance.

5.4 Quality of the land mosaic and acoustic communities and biodiversity.

5.5 Acoustic integrity and connectivity - the degree to which signals can be sensed and interpreted within communities (sonotopes) and allo/ conspecific communication at a landscape scale. 
[d]. Application of acoustic patterns in land management.

Work to date has demonstrated the potential for ecoacoustic methods as a cost-effective proxy for biodiversity. Advances in hardware and software open this non-invasive, and increasingly accessible approach to detect fluctuations in the soundscape. Acoustic patterns that can be revealed through the analysis of environmental sounds are a reliable proxy of the quality of the environment and can be used to monitor processes like urbanization, logging, agriculture intensification as well as restoration, rewilding and reforestation. The new settlement, or the extinction of soniferous species can be ascertained through qualitative and quantitative means by using ecoacoustic methodologies.

\section{[e]. Ecoacoustics and biosemiotics.}

Sound is a biosemiotic vehicle par excellence, utilized in animal communication, for navigation, exploration and habitat selection. Differentiated semiosis and coding/ decoding processes are foundational to ecoacoustic phenomena. The development of new acoustic habits exhibited by soniferous species when reassigned to novel acoustic communities as a consequence of natural or human-induced environmental changes may drive novel competitive interspecific relationships. The same semiotic relations between people and animals can be investigated in an efficient way supporting better approaching strategies to preserve natural processes.

\section{Conclusions}

We have introduced and illustrated key ecoacoustic terminology and concepts in order to highlight the value of ecoacoustics as a discipline in which to conceptualise and study intra- and interspecies soundscape semiosis. Ecoacoustics expands bioacoustics out to the landscape scale, and integrates community and population ecology with individual communication in the study of soundscapes. We have positioned soundscapes within a wider family of sensory scapes (vivoscape, landscape, vibroscape) and stressed their inherently subjective, organism-centred nature. We summarised terms to describe the sources of soundscape components (geophony, biophony, anthropophony, technophony), noting both their shortcomings and their value in advancing the study of soundscapes in theoretical and applied contexts. Soundscape epithets were introduced to point to the degree to which the acoustic environment is implicated in semiosis. The terms acoustic community and acoustic habitat were introduced and illustrated as examples of key ecological structures and processes which have been neglected by both bioacoustics and mainstream ecology previously. The acoustic eco-field was introduced as a semiotic model for understanding how soniferous species intercept core resources such as food and safety.

A predominant focus of ecoacoustic research to date has been the development and validation of metrics that can serve as a proxy for biodiversity and ecosystem status. This applied research remains of primary importance on the ecoacoustic agenda but is itself hampered by theoretical and conceptual immaturity which similarly diminishes the wider endeavour of understanding the role of sound in ecosystem dynamics and 
functioning. By developing a more precise language that is relevant across species and disciplines we hope to focus attention on and investigation of the wide range of ecosystem processes and activities in which acoustic semiosis is central, including assessment of habitat suitability, quality, and transformation, community dynamics, resilience and environmental recovery, signals of environmental stress, relationship with climate, to name just a few. If we consider that sound is a universal semiotic vehicle its study is cross-disciplinary; ecoacoustic nomenclature can benefit disciplines across the sciences, humanities and arts including sound studies and environmental humanities (Maran 2020; Farina 2021). The investigation on focal species and communities should take into consideration a broader agenda where acoustic information may represent an important approach to know the functioning of several ecological processes and their semiosis.

Ecoacoustics is highly relevant to many fields of terrestrial and aquatic ecology. Environmental variables like composition and structure of vegetation, land mosaic arrangement, climatic constraints are some of the families of environmental variables that can be considered under an ecoacoustic approach. In addition, ecoacoustics can be considered a scientific domain with which to open a productive dialogue with ecosemiotics advancements.

Funding Open access funding provided by Università degli Studi di Urbino Carlo Bo.

Open Access This article is licensed under a Creative Commons Attribution 4.0 International License, which permits use, sharing, adaptation, distribution and reproduction in any medium or format, as long as you give appropriate credit to the original author(s) and the source, provide a link to the Creative Commons licence, and indicate if changes were made. The images or other third party material in this article are included in the article's Creative Commons licence, unless indicated otherwise in a credit line to the material. If material is not included in the article's Creative Commons licence and your intended use is not permitted by statutory regulation or exceeds the permitted use, you will need to obtain permission directly from the copyright holder. To view a copy of this licence, visit http://creativecommons.org/licenses/by/4.0/.

\section{References}

Akay, A. (2002). Acoustics of friction. The Journal of the Acoustical Society of America, 111(4), 1525-1548. Allard, H. A. (1930). The first morning song of some birds of Washington, D.C.: Its relation to light. American Naturalist, 64(694), 436-469.

Appel, H. M., \& Cocroft, R. B. (2014). Plants respond to leaf vibrations caused by insect herbivore chewing. Oecologia, 175(4), 1257-1266.

Babisch, W., Beule, B., Schust, M., Kersten, N., \& Ising, H. (2005). Traffic noise and risk of myocardial infarction. Epidemiology, 16, 33-40.

Barber, J. R., Fristrup, K. M., Brown, C. L., Hardy, A. R., Angeloni, L. M., \& Crooks, K. R. (2009). Conserving the wild life therein-protecting park fauna from anthropogenic noise. Park Science, 26(3), 2631.

Barber, J. R., Crooks, K. R., \& Fristrup, K. M. (2010). The costs of chronic noise exposure for terrestrial organisms. Trends in Ecology and Evolution, 25(3), 180-189.

Barbieri, M. (2006). Semantic biology and the mind-body problem. Biological Theory, 1(4), 352-356.

Barbieri, M. (2009). Three types of semiosis. Biosemiotics, 2(1), 19-30.

Betts, M. G., Hadley, A. S., Rodenhouse, N., \& Nocera, J. J. (2008). Social information trumps vegetation structure in breeding-site selection by migrant songbird. Proceedings of the Royal Society B, 275(1648), 2257-2263. 
BirdLife International (2013) Birds are very useful indicators for other kinds of biodiversity. http://www. birdlife.org. Accessed 26 Aug 2020.

Block, B. A. (2005). Physiological ecology in the 21st century: Advancements in biologging science. Integrative and Comparative Biology, 45(2), 305-320.

Borker, A. L., Buxton, R. T., Jones, I. L., Major, H. L., Williams, J. C., Tershy, B. R., \& Croll, D. A. (2019). Do soundscape indices predict landscape-scale restoration outcomes? A comparative study of restored seabird island soundscapes. Restoration Ecology, 28, 252-260. https://doi.org/10.1111/rec.13038.

Boulinier, T., McCoy, K. D., Yoccoz, N. G., Gasparini, J., \& Tveraa, T. (2008). Public information affects breeding dispersal in a colonial bird: Kittiwakes cue on neighbours. Biology Letters, 4(5), 538-540.

Brown, A. L. (2010). Soundscapes and environmental noise management. Noise Control Engineering Journal, 58(5), 493-500.

Brumm, H. (2010). Anthropogenic noise: Implications for conservation. In M. Breed \& J. Moore (Eds.), Encyclopedia of animal behavior (pp. 89-93). Oxford: Oxford Academic Press.

Brumm, H., \& Slabbekoorn, H. (2005). Acoustic communication in noise. In P. J. B. Slater, C. T. Snowdon, T. J. Roper, H. J. Brockmann, \& M. Naguib (Eds.), Advances in the Study of Behavior (Vol. 35, pp. 151209). San Diego: Academic Press.

Brumm, H., \& Slater, P. J. (2006). Ambient noise, motor fatigue, and serial redundancy in chaffinch song. Behavioral Ecology and Sociobiology, 60(4), 475-481.

Brumm, H., \& Todt, D. (2003). Facing the rival: Directional singing behaviour in nightingales. Behaviour, $140(1), 43-53$.

Burt, J. M., \& Vehrencamp, S. L. (2005). 15 - Dawn chorus as an interactive communication network. Animal Communication Networks, 320-343. https://doi.org/10.1017/CBO9780511610363.019.

Cato, D. H. (1978). Marine biological choruses observed in tropical waters near Australia. Journal of the Acoustical Society of America, 64(3), 736-743.

Chan, A. A. Y. H., Giraldo-Perez, P., Smith, S., \& Blumstein, D. T. (2010). Anthropogenic noise affects risk assessment and attention: The distracted prey hypothesis. Biology Letters, 6(4), 458-461.

Clark, W. D., \& Karr, J. R. (1979). Effects of highways on red-winged blackbird and horned lark populations. The Wilson Bulletin, 91(1), 143-145.

Cocroft, R. B., Gogala, M., Hill, P. S. M., \& Wessel, A. (2014). Fostering research progress in a rapidly growing field. In R. B. Cocroft, M. Gogala, P. S. M. Hill, \& A. Wessel (Eds.), Studying vibrational communication (pp. 3-12). Berlin: Springer Verlag.

D’Spain, G. L., \& Batchelor, H. H. (2006). Observations of biological choruses in the southern California bight: A chorus at mid frequencies. Journal of the Acoustical Society of America, 10(4), 1942-1956.

Dabelsteen, T., \& Mathevon, N. (2002). Why do songbirds sing intensively at dawn? Acta Ethologica, 4(2), $65-72$.

Dall, S. R., Giraldeau, L. A., Olsson, O., McNamara, J. M., \& Stephens, D. W. (2005). Information and its use by animals in evolutionary ecology. Trends in Ecology and Evolution, 20(4), 187-193.

Danchin, É., Giraldeau, L.-A., Valone, T. J., \& Wagner, R. H. (2004). Public information: From nosy neighbors to cultural evolution. Science, 305(5683), 487-491.

Davies, W. J., Adams, M. D., Bruce, N. S., Cain, R., Carlile, A., Cusack, P., et al. (2013). Perception of soundscapes: An interdisciplinary approach. Applied Acoustics, 74(2), 224-231.

Deoniziak, K., \& Osiejuk, T. S. (2019). Habitat-related differences in song structure and complexity in a songbird with a large repertoire. BMC Ecology, 19(1), 40.

Depraetere, M., Pavoine, S., Jiguet, F., Gasc, A., Duvail, S., \& Sueur, J. (2012). Monitoring animal diversity using acoustic indices: Implementation in a temperate woodland. Ecological Indicators, 13, 46-54.

Desjonquères, C., Rybak, F., Depraetere, M., Gasc, A., Le Viol, I., et al. (2015). First description of underwater acoustic diversity in three temperate ponds. PeerJ., 3, e1393. https://doi.org/10.7717/peerj. 1393.

Dewry, G. E., \& Rand, S. (1983). Characteristic of an acoustic community: Puerto Rican frogs of the genus Eleutherodactylus. Copeia, 1983(4), 941-953.

Díaz, M., Parra, A., \& Gallardo, C. (2011). Serins respond to anthropogenic noise by increasing vocal activity. Behavioral Ecology, 22(2), 332-336.

Eldridge, A., Casey, M., Moscoso, P., \& Peck, M. (2016). A new method for ecoacoustics? Toward the extraction and evaluation of ecologically-meaningful soundscape components using sparse coding methods. Peer Journals, 4, e2108.

Eldridge, A., Guyot, P., Moscoso, P., Johnston, A., Eyre-Walker, Y., \& Peck, M. (2018). Sounding out ecoacoustic metrics: Avian species richness is predicted by acoustic indices in temperate but not tropical habitats. Ecological Indicators, 95, 939-952. 
Eldridge, A.C., Carruthers-Jones, J., Norum, R. (2020). Sounding wild spaces: Inclusive mapmaking through multispecies listening across scales. In: M. Bull, M. Cobussen (eds). The Bloomsbury: Handbook of sonic methodologies. New York: Bloomsbury academic.

Endler, J. A. (2014). The emerging field of tremology. In R. B. Cocroft, M. Gogala, P. S. M. Hill, \& A. Wessel (Eds.), Studying vibrational communication (pp. VII-X). Berlin: Springer Verlag.

Enfield, N. J., \& Kockelman, P. (2017). Foundations of human interaction: Distributed agency. Oxford: Oxford University Press.

Farina, A. (2006). Principles and methods in landscape ecology. Towards a science of landscape. Dordrecht: Springer.

Farina, A. (2014). Soundscape ecology: Principles, patterns, methods and applications. Dordrecht: Springer.

Farina, A. (2019a). Ecoacoustics: A quantitative approach to investigate the ecological role of environmental sounds. Mathematics, 7(1), 21. https://doi.org/10.3390/math7010021.

Farina, A. (2019b). Hybrid nature: Effects on environmental fundamentals and species' semiosis. Biosemiotics, 13, 21-40.

Farina, A. (2021). Semiotic landscape ecology: A novel approach to reconcile environment and humanities. Cambridge: Cambridge University Press.

Farina, A., \& Belgrano, A. (2004). The eco-field: A new paradigm for landscape ecology. Ecological Research, 19(1), 107-110.

Farina, A., \& Belgrano, A. (2006). The eco-field hypothesis: Toward a cognitive landscape. Landscape Ecology, 21(1), 5-17.

Farina, A., \& Gage, S. H. (2017). Ecoacoustics: A new science. In A. Farina \& S. H. Gage (Eds.), Ecoacoustics: The ecological role of sounds (pp. 1-9). Hoboken: John Wiley and Sons.

Farina, A., \& James, P. (2016). The acoustic communities: Definition, description and ecological role. BioSystems, 147, 11-20.

Farina, A., \& James, P. (2021). Vivo-scapes: An ecosemiotic contribution to the ecological theory. Biosemiotics, in press.

Farina, A., \& Pieretti, N. (2014). From umwelt to soundtope: An epistemological essay on cognitive ecology. Biosemiotics, 7(1), 1-10.

Farina, A., Lattanzi, E., Malavasi, R., Pieretti, N., \& Piccioli, L. (2011). Avian soundscapes and cognitive landscapes: Theory, application and ecological perspectives. Landscape Ecology, 26(9), 1257-1267.

Farina, A., Pieretti, N., Salutari, P., Tognari, E., \& Lombardi, A. (2016). The application of the acoustic complexity indices (ACI) to ecoacoustic event detection and identification (EEDI) modeling. Biosemiotics, 9(2), 227-246.

Farina, A., Gage, S. H., \& Salutari, P. (2018). Testing the ecoacoustics event detection and identification (EEDI) model on Mediterranean soundscapes. Ecological Indicators, 85, 698-715.

Farina, A., Righini, R., Fuller, S., Li, P., \& Pavan, G. (2021). Acoustic complexity indices reveal the acoustic communities of the old-growth Mediterranean forest of Sasso Fratino integral natural reserve (Central Italy). Ecological Indicators, 120, 106927.

Fletcher, N. H. (2007). Animal bioacoustics. In T. D. Rossing (Ed.), Handbook of acoustics (pp. 785-804). New York: Springer.

Francis, C. D., \& Barber, J. R. (2013). A framework for understanding noise impacts on wildlife: An urgent conservation priority. Frontiers in Ecology and the Environment, 11(6), 305-313.

Francis, C. D., Ortega, C. P., \& Cruz, A. (2009). Noise pollution changes avian communities and species interactions. Current Biology, 19(16), 1415-1419.

Francis, C. D., Newman, P., Taff, B. D., White, C., Monz, C. A., Levenhagen, M., \& Cooper, C. B. (2017). Acoustic environments matter: Synergistic benefits to humans and ecological communities. Journal of Environmental Management, 203, 245-254.

Frisk, G. V. (2012). Noiseonomics: The relationship between ambient noise levels in the sea and global economic trends. Scientific Reports, 2, 437.

Gage, S. H., \& Axel, A. C. (2013). Visualization of temporal change in soundscape power of a Michigan lake habitat over a 4-year period. Ecological Informatics, 21, 100-109.

Gasc, A., Sueur, J., Pavoine, S., Pellens, R., \& Grandcolas, P. (2013a). Biodiversity sampling using a global acoustic approach: Contrasting sites with microendemics in New Caledonia. PLoS ONE, 8(5), e65311, 110. https://doi.org/10.1371/journal.

Gasc, A., Sueur, J., Jiguet, F., Devictor, V., Grandcolas, P., Burrow, C., \& Pavoine, S. (2013b). Assessing biodiversity with sound: Do acoustic diversity indices reflect phylogenetic and functional diversities of bird communities? Ecological Indicators, 25, 279-287.

Gibb, R., Mac, O., \& Jones, K. (2016). Bat detective: Citizen science for eco-acoustic biodiversity monitoring. Environmental Scientist, 25(2), 15-18. 
Gil, D., Honarmand, M., Pascual, J., Perez-Mena, E., \& Macias Garcia, C. (2015). Birds living near airports advance their dawn chorus and reduce overlap with aircraft noise. Behavioral Ecology, 26(2), 435-443. https://doi.org/10.1093/beheco/aru207.

Grant, P. B. C., \& Samways, M. J. (2016). Use of ecoacousics to determine biodiversity patterns across ecological gradients. Conservation Biology, 30(6), 1320-1329.

Greenfield, M., Esquer-Garrigos, Y., Streiff, R., \& Party, V. (2016). Animal choruses emerge from receiver psychology. Scientific Reports, 6, 34369. https://doi.org/10.1038/srep34369.

Hahn, B. A., \& Silverman, E. D. (2006). Social cues facilitate habitat selection: American redstarts establish breeding territories in response to song. Biology Letters, 2(3), 337-340.

Hahn, B. A., \& Silverman, E. D. (2007). Managing breeding forest songbirds with conspecific song playbacks. Animal Conservation, 10(4), 436-441.

Hall, L. S., Krausman, P. R., \& Morrison, M. L. (1997). The habitat concept and a plea for standard terminology. Wildlife Society Bulletin, 25(1), 173-182.

Harris, S. A., Shears, N. T., \& Radford, C. A. (2016). Ecoacoustics indices as proxies for biodiversity on temperate reefs. Methods in Ecology and Evolution, 7(6), 713-724.

Hauser, M. D. (1996). The evolution of communication. Cambridge: MIT press.

Hill, P. S. (2008). Vibrational communication in animals. Cambridge: Harvard University Press.

Hill, P. S. (2009). How do animals use substrate-borne vibrations as an information source? Naturwissenschaften, 96(12), 1355-1371.

Hill, A. P., Prince, P., Piña Covarrubias, E., Doncaster, C. P., Snaddon, J. L., \& Rogers, A. (2018). AudioMoth: Evaluation of a smart open acoustic device for monitoring biodiversity and the environment. Methods in Ecology and Evolution, 9(5), 1199-1211.

Hill, P. S., Lakes-Harlan, R., Mazzoni, V., Narins, P. M., Virant-Doberlet, M., Wessel, A. (Eds.). (2019). Biotremology: Studying vibrational behavior. Springer International Publishing.

Ideker, T., Dutkowski, J., \& Hood, L. (2011). Boosting signal-to-noise in complex biology: Prior knowledge is power. Cell, $144(6), 860-863$.

Jeffs, A., Tolimieri, N., \& Montgomery, J. C. (2003). Crabs on cue for the coast: The use of underwater sound for orientation by pelagic crab stages. Marine and Freshwater Research, 54(7), 841-845.

Kay, P., \& Kempton, W. (1984). What is the Sapir-Whorf hypothesis? American Anthropologist, 86(1), 6579.

Krause, B. L. (1993). The niche hypothesis: A virtual symphony of animal sounds, the origins of musical expression and the health of habitats. The Soundscape Newsletter, 6, 6-10.

Krause, B., \& Farina, A. (2016). Using ecoacoustic methods to survey the impacts of climate change on biodiversity. Biological Conservation, 195, 245-254.

Kroodsma, D. E., \& Miller, E. H. (Eds.). (1996). Ecology and evolution of acoustic communication in birds. Ithaca: Cornell University Press.

Lellouch, L., Pavoine, S., Jiguet, F., Glotin, H., \& Sueur, J. (2014). Monitoring temporal change of bird communities with dissimilarity acoustic indices. Methods in Ecology and Evolution, 5, 495-505.

Lemon, R. E., Struger, J., Lechowicz, M. J., \& Norman, R. F. (1981). Song features and singing heights of American warblers. Maximization or optimization of distance? The Journal of the Acoustical Society of America, 69(4), 1169-1176.

Leopold, A., \& Eynon, A. E. (1961). Avian daybreak and evening song in relation to time and light intensity. Condor, 63(4), 269-293.

Lombard, E. (1911). Le signe de l'elevation de la voix. Ann Mal Oreil Larynx, 37, 101-199.

Lupo, C., Lodi, L., Paluffi, G., \& Viti, A. (1991). Central and peripheral endocrine correlates of the immobility reaction in the toad Bufo bufo. Behavioural Processes, 24(1), 1-7.

Luther, D. (2009). The influence of the acoustic community on songs of birds in a neotropical rain forest. Behavioral Ecology, 20(4), 864-871.

Luther, D., \& Gentry, K. (2013). Sources of background noise and their influence on vertebrate acoustic communication. Behaviour, 150(9-10), 1045-1068.

MacDougall-Shackleton, S. A., Hulse, S. H., Gentner, T. Q., \& White, W. (1998). Auditory scene analysis by European starlings (Sturnus vulgaris): Perceptual segregation of tone sequences. The Journal of the Acoustical Society of America, 103(6), 3581-3587.

Madden, N., \& Jehle, R. (2017). Acoustic orientation in the great crested newt (Triturus cristatus). AmphibiaReptilia, 38(1), 57-65.

Magrini, A., \& Lisot, A. (2015). Noise reduction interventions in the urban environment as a form of control of indoor noise levels. Energy Procedia, 78, 1653-1658.

Malavasi, R., \& Farina, A. (2013). Neighbours' talk: Interspecific choruses among songbirds. Bioacoustics, $22(1), 33-48$. 
Mallarach, J. M. (Ed.). (2008). Protected landscapes and cultural and spiritual values (Vol. 2). Kasparek: Verlag.

Mandelbrot, B. (1983). The fractal geometry of nature. New York: Freeman.

Maran, T. (2020). Ecological repertoire analysis: A method of interaction-based semiotic study for multispecies environments. Biosemiotics, 13, 63-75.

Marten, K., \& Marler, P. (1977). Sound transmission and its significance for animal vocalization. Behavioral Ecology and Sociobiology, 2, 271-290.

Maturana, H. R., \& Varela, F. J. (1991). Autopoiesis and cognition: The realization of the living. Springer science and business media.

Mönkkönen, M., Helle, P., \& Soppela, K. (1990). Numerical and behavioural responses of migrant passerines to experimental manipulation of resident tits (Parus spp.): Heterospecific attraction in northern breeding bird communites? Oecologia, 85(2), 218-225.

Morton, E. (1975). Ecological sources of selection on avian sounds. The American Naturalist, 109(965), 1734.

Morton, E. S. (1986). Predictions from the ranging hypothesis for the evolution of long distance signals in birds. Behaviour, 99(1-2), 65-86.

Mukhin, A. L., Chernetsov, N. S., \& Kishkinev, D. A. (2005). Reed warbler, Acrocephalus scirpaceus (Aves, Sylviidae), song as an acoustic marker of wetland biotope during migration. Zoologicheskiü Zhurnal, 84, 995-1002.

Mukhin, A., Nikita, C. \& , Kishkinev, D. (2005). Acoustic information as a distant cue for habitat recognition by nocturnally migrating passerines during landfall. Behavioral Ecology, 19(4), 716-723.

Mullet, T. C., Farina, A., \& Gage, S. H. (2017). The acoustic habitat hypothesis: An ecoacoustics perspective on species habitat selection. Biosemiotics, 10(3), 319-336.

Narins, P. M., Feng, A. S., Lin, W., Schnitzler, H. U., Denzinger, A., Suthers, R. A., \& Xu, C. (2004). Old World frog and bird vocalizations contain prominent ultrasonic harmonics. The Journal of the Acoustical Society of America, 115(2), 910-913.

Narins, P. M., Stoeger, A. S., \& O'Connell-Rodwell, C. (2016). Infrasonic and seismic communication in the vertebrates with special emphasis on the Afroteria; an update and future directions. In R. A. Suthers, W. T. Fitch, R. R. Fay, \& A. N. Popper (Eds.), Vertebrate sound production and acoustic communication (pp. 191-227). Heidelberg: Springer Verlag.

Niessen, M., Cance, C., Dubois, D. (2010). Categories for soundscape: Toward a hybrid classification. In: Inter-noise and noise-con congress and conference proceedings (Vol. 2010, no. 5, pp. 5816-5829). Institute of Noise Control Engineering.

Ortega, C. P. (2012). Chapter 2: Effects of noise pollution on birds: A brief review of our knowledge. Ornithological Monographs, 74(1), 6-22.

Pijanowski, B. C., Villanueva-Rivera, L. J., Dumyahn, S. L., Farina, A., Krause, B., Napoletano, B. M., Gage, S. H., \& Pieretti, N. (2011a). Soundscape ecology: The science of sound in the landscape. Bioscience, 61(3), 203-216.

Pijanowski, B. C., Farina, A., Dumyahn, S. L., Krause, B. L., \& Gage, S. H. (2011b). What is soundscape ecology? Landscape Ecology, 26(9), 1213-1232.

Polajnar, J., \& Virant-Doberlet, M. (2019). Practical issues in studying natural Vibroscape and biotic noise. In: P. Hill, R. Lakes-Harlan, V. Mazzoni, P.M. Narins, M. Virant-Doberlet, A. Wessel, A. (Eds.), Biotremology: Studying Vibrational Behavior (pp. 125-148). Cham: Springer Nature.

Potash, L. M. (1972). Noise-induced changes in calls of the Japanese quail. Psychonomic Science, 26(5), 252254.

Price, P. W. (1984). Insect ecology (2nd ed.). New York: Wiley Interscience.

Prideaux, G., \& Prideaux, M. (2016). Environmental impact assessment guidelines for offshore petroleum exploration seismic surveys. Impact Assessment and Project Appraisal, 34(1), 33-43.

Qi, J., Gage, S. H., Joo, W., Napoletano, B., \& Biswas, S. (2008). Soundscape characteristics of an environment: A new ecological indicator of ecosystem health. In W. Ji (Ed.), Wetland and water resource modeling and assessment (pp. 201-211). CRC Press: New York.

Rabin, L. A., Coss, R. G., \& Owings, D. H. (2006). The effects of wind turbines on antipredator behavior in California ground squirrels (Spermophilus beecheyi). Biological Conservation, 131(3), 410-420.

Rappaport, D. I., Royle, A., \& Morton, D. C. (2020). Acoustic space occupancy: Combining ecoacoustics and lidar to model biodiversity variation and detection bias across heterogeneous landscapes. Ecological Indicators, 113, 106172.

Reading, A. (2011). Meaningful information. New York: Springer.

Reguera, G. (2011). When microbial conversations get physical. Trends in Microbiology, 19(3), 105-113. https://doi.org/10.1016/j.tim.2010.12.007. 
Ringler, M., Szipl, G., Hödl, W., Khil, L., Kofler, B., Lonauer, M., \& Ringler, E. (2017). Acoustic ranging in poison frogs-It is not about signal amplitude alone. Behavioral Ecology and Sociobiology, 71(8), 114.

Sakazaki, T., \& Hamilton, K. (2020). An array of ringing global free modes discovered in tropical surface pressure data. Journal of the Atmospheric Sciences, 77(7), 2519-2539.

Scales, J. A., \& Snieder, R. (1998). What is noise? Geophysics, 63(4), 1122-1124.

Schafer, R. M. (1977). The soundscape: Our sonic environment and the tuning of the world. Rochester: Destiny Books.

Shannon, C. E. (1948). A mathematical theory of communication. Bell System Tech. J., 27, 379-423.

Shannon, C. E., \& Weaver, W. (1949). The mathematical theory of communication. Urban and Chicago: University of Illinois Press.

Shaver, J. M., \& Walker, G. (1930). A preliminary study of the effects of temperature on the time of ending of the evening song of the monckingbird. Auk, 47(3), 385-396.

Simpson, S. D., Meekan, M., Montgomery, J., McCauley, R., \& Jeffs, A. (2005). Homeward sound. Science, 308(5719), 221.

Simpson, S. D., Meekan, M., Jeffs, A., Montgomery, J., \& McCauley, R. (2008). Settlement-stage coral reef fish prefer the higher-frequency invertebrate-generated audible component of reef noise. Animal Behaviour, 75(6), 1861-1868.

Slabbekoorn, H. (2004). Habitat-dependent ambient noise: Consistent spectral profiles in two African forest types. The Journal of the Acoustical Society of America, 116(6), 3727-3733.

Sørensen, T. (1936). Some ecosystematical characteristics determined by Raunkiær's circling method. Nordiska (19. skandinaviska) naturforskarmöteti Helsingfors den, 11-15.

Staicer, C. A., Spector, D. A., \& Horn, A. G. (1996). The dawn chorus and other diel patterns in acoustic signaling. In D. E. Kroodsma \& E. H. Miller (Eds.), Ecology and evolution of acoustic communication in birds (pp. 426-453). New York: Cornell University Press.

Šturm, R., Polajnar, J., López Díez, J.J., Sueur, J., \& Virant-Doberlet, M. (2018). Is it time for ecotremology? In: P.S.M. Hill, V. Mazzon, and M. Virant-Doberlet (eds.), Abstract book, 2nd international symposium on biotremology (pp. 52). Riva del Garda, Italy.

Sueur, J., \& Farina, A. (2015). Ecoacoustics: The ecological investigation and interpretation of environmental sound. Biosemiotics, 8(3), 493-502.

Sueur, J., Pavoine, S., Hamerlynck, O., \& Duvail, S. (2008). Rapid acoustic survey for biodiversity appraisal. PLoS One, 3, e4065. https://doi.org/10.1371/journal.pone.0004065.

Sueur, J., Farina, A., Gasc, A., Pieretti, N., \& Pavoine, S. (2014). Acoustic indices for biodiversity assessment and landscape investigation. Acta Acustica united with Acustica, 100, 772-781.

Sueur, J., Krause, B., \& Farina, A. (2019). Climate change is breaking Earth's beat. Trends in Ecology and Evolution, 34(11), 971-973.

Sugi, T., Igarashi, R., \& Nishimura, M. (2018). Noninvasive mechanochemical imaging in unconstrained Caenophabditis elegans. Materials, 11, 2013. https://doi.org/10.3390/ma11061034.

Tansley, A. G. (1939). The British Isles and their vegetation (Vol. 1 of 2). Cambridge: Cambridge University Press.

Thomson, R. L., Forsman, J. T., \& Mönkkönen, M. (2003). Positive interactions between migrant and resident birds: Testing the heterospecific attraction hypothesis. Oecologia, 134(3), 431-438.

Todt, D., \& Naguib, M. (2000). Vocal interactions in birds: The use of song as a model in communication. Advances in the Study of Behavior, 29, 247-296.

Tolimieri, N., Jeffs, A., \& Montgomery, J. C. (2000). Ambient sound as a cue for navigation by the pelagic larvae of reef fishes. Marine Ecology Progress Series, 207, 219-224.

Tønnessen, M. (2009). Umwelt transitions: Uexküll and environmental change. Biosemiotics, 2, 47-64.

Tønnessen, M., Maran, T., \& Sharov, A. (2018). Phenomenology and biosemiotics. Biosemiotics, 11(3), 323330.

Truax, B. (Ed.). (1999). Handbook for acoustic ecology. Cambridge: Cambridge Street Publishing.

Tucker, D., Gage, S. H., Williamson, I., \& Fuller, S. (2014). Linking ecological condition and the soundscape in fragmented Australian forests. Landscape Ecology, 29(4), 745-758.

Vermeij, M. J., \& Bak, R. P. (2002). Corals on the move: Rambling of Madracis pharensis polyps early after settlement. Coral Reefs, 21(3), 262-290.

Virant-Doberlet, M., Kuhelj, A., Polajnar, J., \& Šturm, R. (2019). Predator-prey interactions and eavesdropping in vibrational communication networks. Frontiers in Ecology and Evolution, 7, 203.

Von Uexküll, J. (1926). Theoretical biology. London: Kegan, Paul, Trench, Trubner and Company Ltd.

Von Uexküll, J. (1982). (1940). The theory of meaning. Semiotica, 42, 25-82.

Von Uexküll, J. (1992). (1934). A stroll through the worlds of animals and men. Semiotica, 89(4) 702, 319391. 
Walker, T. J. (1969). Acoustic synchrony: Two mechanisms in the snowy tree cricket. Science, 166(3907), 891-894.

Wallschläger, D. (1980). Correlation of song frequency and body weight in passerine birds. Experientia, 36(4), 412-412.

Ward, M. P., \& Schlossberg, S. (2004). Conspecific attraction and the conversation of territorial songbirds. Conservation Biology, 18(2), 519-525.

Westerkamp, H. (2002). Linking soundscape composition and acoustic ecology. Organised Sound, 7(1), 5156.

Whitfield, A. K., \& Becker, A. (2014). Impacts of recreational motorboats on fishes: A review. Marine Pollution Bulletin, 83(1), 24-31.

Whittaker, R. H. (1960). Vegetation of the Siskiyou mountains, Oregon and California. Ecological Monographs, 30(3), 279-338.

Whorf, B. (1956). Language, thought, and reality. In J. Carroll (Ed.), Selected Writings (pp. 615-632). New York: John Wiley and Sons.

Wiens, J. A., \& Milne, B. T. (1989). Scaling of 'landscapes' in landscape ecology, or, landscape ecology from a beetle's perspective. Landscape Ecology, 3(2), 87-96.

Wiley, R. H. (1994). Errors, exaggeration, and deception. In L. A. Real (Ed.), Behavioral mechanisms in evolutionary ecology (p. 157). Chicago: The University of Chicago Press.

Wright, H. W. (1912). Morning awakening and even-song. Auk, 29(3), 307-327.

Wright, H. W. (1913). Morning awakening and even-song: Second paper. Auk, 30(4), 512-537.

Wrightson, K. (2000). An introduction to acoustic ecology. Soundscape: The Journal of Acoustic Ecology, 1(1), 10-13.

Publisher's Note Springer Nature remains neutral with regard to jurisdictional claims in published maps and institutional affiliations.

\section{Affiliations}

\section{Almo Farina ${ }^{1} \cdot$ Alice Eldridge $^{2} \cdot{\text { Peng } \mathrm{Li}^{3}}^{3}$}

1 Department of Pure and Applied Sciences, University of Urbino, Urbino, PU, Italy

2 Department of Music, University of Sussex, Brighton BN1 9QN, UK

3 Division of Sleep and Circadian Disorders, Brigham and Women's Hospital, Harvard Medical School, Boston, USA 